\title{
Abdominal pain as the initial and sole clinical presenting feature of systemic lupus erythematosus
}

\author{
Henry V Chung MD ${ }^{1}$, Alnoor Ramji MD FRCPC ${ }^{1}$, Jennifer E Davis MB ChB FRCPC ${ }^{2}$, Sylvia Chang MD FRCPC ${ }^{3}$, \\ Graham D Reid MB ChB FRCPC ${ }^{1}$, Baljinder Salh MB ChB FRCPC ${ }^{1}$, Hugh J Freeman MDCM FRCPC ${ }^{1}$, \\ Eric M Yoshida MD MHSC FRCPC ${ }^{1}$
}

\begin{abstract}
H V Chung, A Ramji, JE Davis, et al. A bdominal pain as the initial and sole clinical presenting feature of systemic lupus erythematosus. C an J G astroenterol 17(2):111-113.

Classically, a diagnosis of systemic lupus erythematosus (SLE) is dependent on renal, rheumatological, cutaneous and neurological target organ damage with supporting serological markers. A previously healthy 26-year-old Japanese woman whose only manifestation of otherwise occult SLE was severe abdominal pain is reported. A computed tomographic scan of the abdomen revealed thickened loops of small bowel, endoscopic findings were nonspecific and jejunal biopsy revealed a nonspecific enteritis. Laboratory studies revealed lymphopenia, hypocomplementemia, a positive antinuclear antibody, a weakly positive anti-Smith and a strongly positive anti-double stranded DNA. There was a prompt symptomatic recovery with immunosuppressive therapy. The authors' experiences, and a review of the literature suggest that a diagn osis of SLE should be considered in young A sian women who present with significant but clinically enigmatic gastrointestinal illness.
\end{abstract}

Key W ords: A bdominal pain; Systemic lupus erythematosus

\section{L a douleur abdominale comme caractéristique initiale et unique de lupus érythémateux disséminé à la présentation}

D'ordinaire, un diagnostic de lupus érythémateux disséminé (LÉD) dépend de dommages rénaux, rhumatologiques, cutanés et neurologiques d'un organe cible et de marqueurs sérologiques. 0 n présente le cas d'une Japonaise de 27 ans auparavant en santé dont le LÉD autrement occulte se manifestait seulement par de graves douleurs abdominales. U ne tomodensitométrie de l'abdomen a révélé des anses épaissies de l'intestin grêle, les observations endoscopiques n'étaient pas spécifiques et la biopsie jéjunale a démontré la présence d'une entérite non spécifique. Les études de laboratoire ont révélé une lymphocytopénie, une hypocomplémentémie, un anticorps antinucléaire positif, un anti-Smith légèrement positif et un brin d'A DN antidouble. Les symptômes ont rapidement disparu grâce à la prise d'immunosuppresseurs. D après les expériences de l'auteur et un examen de la documentation scientifique, un diagnostic de LÉD devrait être envisagé chez les jeunes femmes asiatiques qui se présentent avec une maladie gastro-intestinale importante, silencieuse du point de vue clinique.
A bdominal pain is a very common medical complaint, and accounts for a significant number of primary care physician visits and referrals to gastroenterologists. In one survey, $21.8 \%$ of respondents reported abdominal pain in the preceding one month, and more than $65 \%$ rated the symptoms as either moderate or severe (1). We report a case of a patient who presented with severe abdominal pain that was the initial clinical manifestation of occult systemic lupus erythematosus (SLE).

\section{CASE PRESENTATION}

A previously healthy 26-year-old Japanese woman presented with diffuse, colicky central abdominal pain, a four-week history of frequent nonbloody, soft stools, a two-week history of anorexia and fatigue and a three-day history of fever, nausea and vomiting. M ovement aggravated her pain and there were no relieving factors. There was no melena, bloody diarrhea, night sweats, arthralgias, skin rashes, photosensitivity, headaches, visual disturbances, dyspnea, chest pain, Raynaud's phenomena, sicca symptoms or changes to her bladder habits. She did note a $2.3 \mathrm{~kg}$ weight loss over the past three months. $M$ edications before presentation included oral contraceptives and occasional ibuprofen or acetaminophen. She did not smoke or consume alcohol and the family history was unremarkable. On examination, she was afebrile. Head, neck and cardiopulmonary examinations were unremarkable. The abdomen was soft but tender over the epigastrum without rebound. There was no stigmata of chronic liver disease, hepatosplenomegaly, masses or significant distention. A rheumatological examination revealed no abnormalities and a dermatological survey was un remarkable.

Laboratory investigations revealed a leukocyte count of $6.1 \times 10^{9} / \mathrm{L}$ with a decreased lymphocyte count of $0.5 \times 10^{9} / \mathrm{L}$ (normal range: 1.2-3.0×109/L ), hemoglobin $139 \mathrm{~g} / \mathrm{L}$, and platelet count of $208 \times 10^{9} / \mathrm{L}$. Serum electrolytes revealed a mild hypokalemia of $3.4 \mathrm{mmol} / \mathrm{L}$ (normal range $3.5-5.0 \mathrm{mmol} / \mathrm{L}$ ), urea $3.8 \mathrm{mmol} / \mathrm{L}$ and serum creatinine was $68 \mu \mathrm{mol} / \mathrm{L}$. Serum amylase and liver enzymes were normal. The serum albumin was decreased at $27 \mathrm{~g} / \mathrm{L}$ (normal range 34 to $50 \mathrm{~g} / \mathrm{L}$ ). Routine urinalysis initially revealed trace proteins on dipstick but was negative on repeated urinalysis. Stool cultures and hepatitis $A$, $B$ and $C$ serology were negative.

The chest $x$-ray revealed small bilateral pleural effusions. A $n$ ultrasound of the abdomen revealed diffuse small bowel

D epartments of ${ }^{1} \mathrm{M}$ edicine, ${ }^{2} \mathrm{~A}$ natomic Pathology and ${ }^{3}$ Radiology, U niversity of B ritish C olumbia, Vancouver, B ritish $\mathrm{C}$ olumbia

C orrespondence: Dr E ric M Yoshida, Vancouver G eneral H ospital, Division of G astroenterology, 100-2647 W illow Street, Vancouver,

British C olumbia V 5Z 3P1. Telephone 604-875-5371, fax 604-875-5447, e-mail eyoshida@interchange. ubc.ca

Received for publication A ugust 14, 2002. A ccepted N ovember 8, 2002 


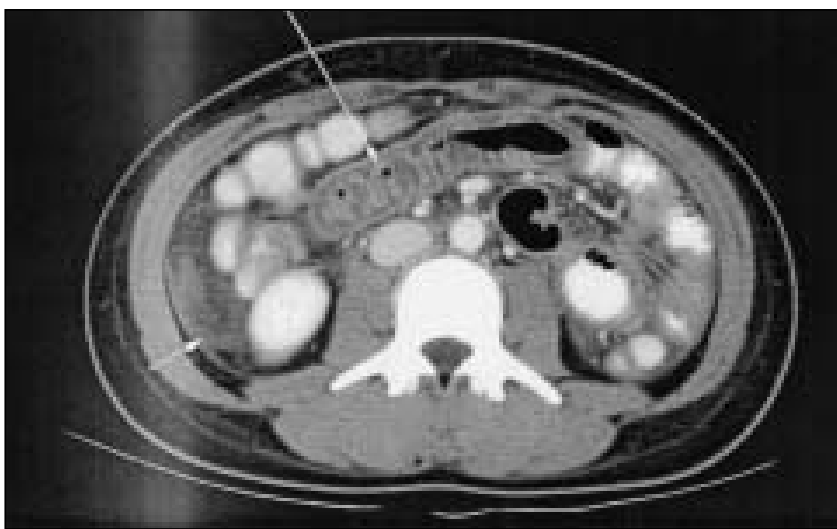

Figure 1) C ontrast-enhanced computed tomography of the abdomen demonstrates circumferential bowel wall thickening involving a segment of jejunum (long arrow). A small amount of ascites is also present in the right paracolic gutter (short arrow)

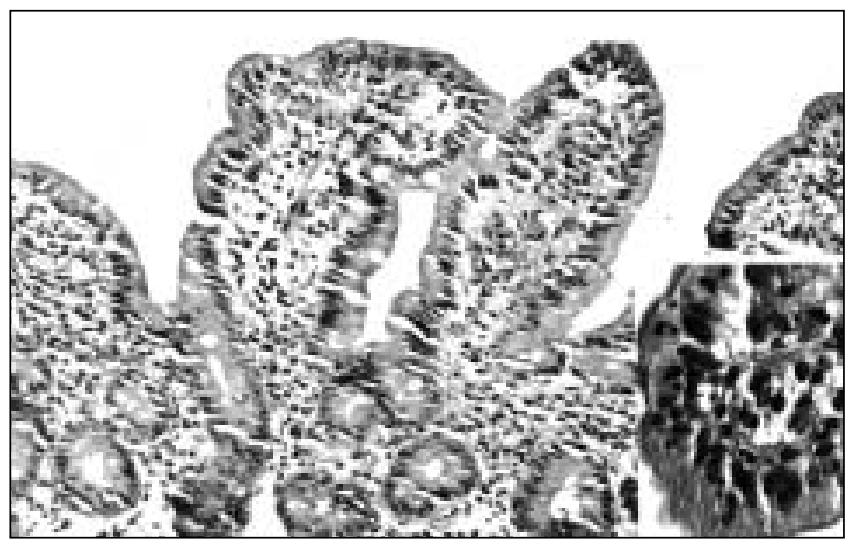

Figure 2) Duodenal biopsy ( $\mathrm{H}$ ematoxylin and eosin, original magnification $\times 252$; inset original magnification $\times 608$ ). T he architecture is normal. There is a neutrophilic infiltrate in the superficial epithelium, predominantly in the tips of the villi, and a mild increase in lymphocytes in the deeper glands (inset). T here are no infective agents or viral cytopathic effects

thickening and moderate ascites. A computed tomography of the abdomen (Figure 1) confirmed these findings. U pper gastrointestinal endoscopy was normal and the biopsy of the jejunum (Figure 2) revealed a nonspecific inflammatory infiltrate. Colonoscopy and biopsies of the colon and terminal ileum did not reveal any abnormalities. Echocardiography was unremarkable. A mesenteric angiogram was performed that did not show any evidence of vasculitis on selective celiac, superior mesenteric and bilateral renal selections.

Further laboratory investigatons revealed that the $\mathrm{C} 3$ and C 4 were decreased at $0.48 \mathrm{~g} / \mathrm{L}$ (normal range 0.80 to $1.80 \mathrm{~g} / \mathrm{L}$ ) and $0.05 \mathrm{~g} / \mathrm{L}$ (normal range 0.12 to $0.36 \mathrm{~g} / \mathrm{L}$ ) respectively. The antinuclear antibody titre was positive at 1:160 with a mixed homogenous and speckled pattern. The extractable nuclear antigens (Quanta Life ${ }^{T M}$ ELISA; Inova Diagnostics, USA) revealed a weakly positive anti Smith, anti- SCL 70, and antiSSB. The anti-double stranded DN A was strongly positive at $986 \mathrm{IU} / \mathrm{mL}$ (strong positive greater than $801 \mathrm{IU} / \mathrm{mL}$ ) as was the anti-SSA at 193.8 EU (strong positive greater than $80 \mathrm{EU}$ ) A diagnosis of SLE of the small bowel was made. Her oral con- traceptives were discontinued upon admission to hospital, but this did not did not change her symptoms. Treatment consisted of azathioprine $50 \mathrm{mg}$ and prednisone $20 \mathrm{mg}$ daily with a prompt resolution of symptoms. Two months after her initial presentation she experienced two episodes of right sided amaurosis fugax. Tests for anticardiolipin antibodies and delayed Russel venom viper test (DRVVT) were negative. Carotid ultrasound, cardiac echocardiogram and magnetic resonance angiography were negative. A cetylsalicylic acid was added to the regimen.

\section{DISC U SSION}

SLE is a common disorder that affects one in 2500 people, with a female predominance (2). The classification (but not clinical diagnosis) of SLE is typically based on the 1982 revised criteria of the A merican Rheumatologic A ssociaton (ARA) for the classification of SLE (3), which is reported to be $96 \%$ sensitive and $96 \%$ specific. The A RA critieria require a serial or simultaneous presentation of four of 11 listed symptoms, signs or laboratory findings for a diagnosis of lupus (3). O ur patient met minimal ARA diagnostic criteria of SLE but did not have any of the classic renal, dermatological (ie, malar or discoid rash), musculoskeletal (ie, polyarthrititis) or neurological features that are included in the ARA criteria. M oreover, evidence of serositis (ie, pleural effusion, ascites) was apparent only on diagnostic imaging. A bdominal pain and evidence of gastrointestinal disease are not included in the A RA criteria but in our patient's case, a diagnosis of SLE was confirmed by her lymphopenia, hypocomplementemia, positive antinuclear antibody and strongly positive anti-double stranded DNA, anti-SSA, as well as the weakly positive anti-Smith. Therefore, we are confident that her clinical diagnosis was SLE.

Gastrointestinal manifestations of SLE that have been reported in the literature consist of abdominal pain, nausea, vomiting and diarrhea, and are reported to occur in greater than $50 \%$ of SLE patients at some time during the course of the disease (4). A bdominal pain during a lupus flare is usually attributed to polyserositis. In cases of acute abdominal pain, a study of 31 of 39 abdominal computed tomographic scans in known SLE patients were suggestive of ischemic bowel (5). However, abdominal pain without evidence of active lupus tends to be caused by non-SLE-associated gastrointestinal illnesses (6). The unique aspect of this case is that abdominal pain was the only clinical manifestation of otherwise occult SLE. It was only after specific rheumatological laboratory investigations were performed during the investigation of otherwise 'abdominal pain not yet diagnosed' did the diagnosis of SLE become revealed. To our knowledge there have been no similar cases described in the literature. The abdominal pain was most likely secondary to either mechanical stimulation of visceral pain receptors secondary to the bowel edema, or due to the release of inflammatory mediators that stimulated the mucosal receptors.

Interestingly, the patient also presented with clinically mild ascites, small pleural effusions and hypoalbuminemia. A Ithough she did have a suggestion of proteinuria on an initial urinalysis, subsequent urinalysis failed to demonstrate an ongoing renal protein loss. Therefore, we feel that in light of the bowel wall thickening and the hypoalbuminemia that there was also an SLE-associated protein-losing enteropathy (PLE). 
U nfortunately, a Tc-99 labelled albumin to demonstrate protein loss from the gastrointestinal tract was unavailable, due to a lack of reagent, at the time of initial hospitalization. Of some interest, at our institution, a previous case involving a young A sian woman who was found to have a painless lupus-associated PLE as the first manifestation of otherwise occult SLE was recently reported (7). A nother study reported that nine of 22 cases in the literature of autoimmune associated PLE were from Japan (8). Thus, we speculate that gastrointestinal lupus may be more common in women of A sian-Pacific descent.

A Ithough abdominal pain is a very common complaint in patients with either an established diagnosis of SLE or classic A RA target organ damage, our experience suggests that it may be the initial clinical manifestation of otherwise occult lupus. Furthermore, we suggest that the diagnosis of lupus should be considered when a young A sian woman presents with abdominal pain and unexplained enteropathy because rapid symptomatic improvement may occur with the administration of immunosuppresant therapy.

\section{REFEREN CES}

1. Sandler RS, Stewart W F, Liberman JN, Ricci JA, Zorich N L. A bdominal pain, bloating, and diarrhea in the U nited States: Prevalence and impact. Digest Dis Sci 2000;45:1166-71.

2. M ills JE. Systemic lupus erythematosus. N Engl J M ed 1994;330:1871-9.

3. Tan EM, Cohen ES, Fries JF, et al. The 1982 revised criteria for the classification of systemic lupus erythematosus. A rthritis R heum 1982;78:1271-7.

4. Papa M Z, Shiloni E, M cD onald HD. Total colonic necrosis: A catastrophic complication of systemic lupus erythematosus. Dis Colon Rectum 1986;29:576-8.

5. Byun JY, H a HK, Yu SY, et al. CT Features of systemic lupus erythematosus in patients with acute abdominal pain: Emphasis on ischemic bowel disease. Radiology 1999;211:203-9.

6. van H oek B. The spectrum of liver disease in systemic lupus erythematosus. N etherlands J M ed 1996;48:244-53.

7. N orthcott KA, Yoshida EM, Steinbrecher U P. Primary protein losing enteropathy in anti-double-stranded DN A disease: The initial and sole clinical manifestation of occult systemic lupus erythematosus? J C lin G astroenterol 2001;33:340-1.

8. N akajima A, O hnishi S, M imura T, et al. Protein-losing enteropathy associated with hypocomplementemia and antinuclear antibodies. J G astroenterol 2000;35:627-30. 


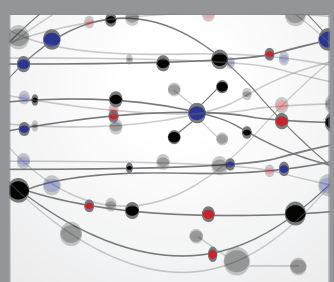

The Scientific World Journal
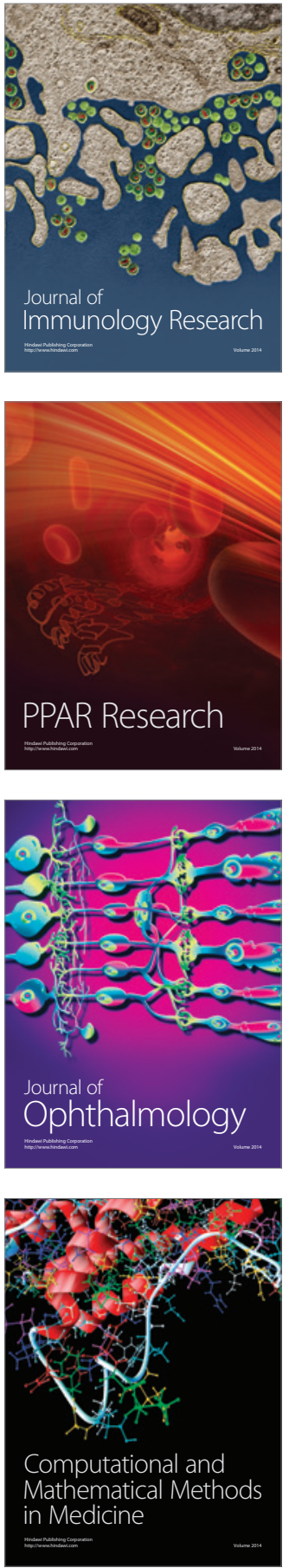

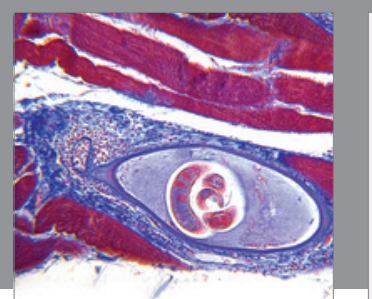

Gastroenterology Research and Practice

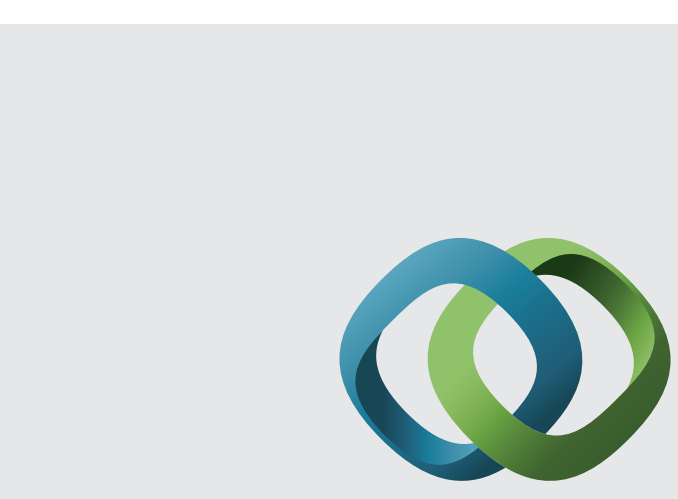

\section{Hindawi}

Submit your manuscripts at

http://www.hindawi.com
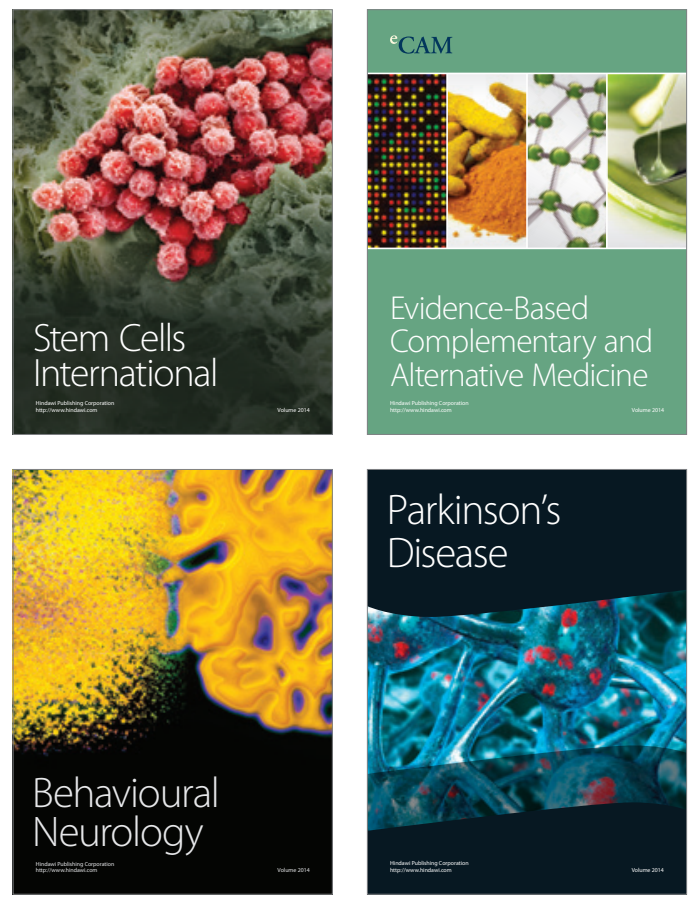
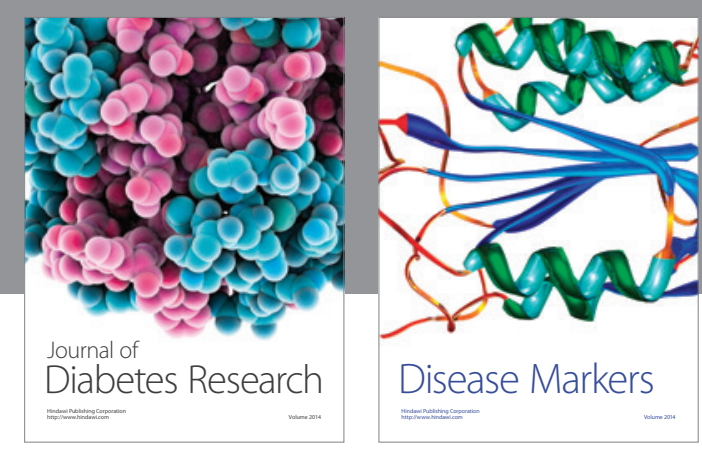

Disease Markers
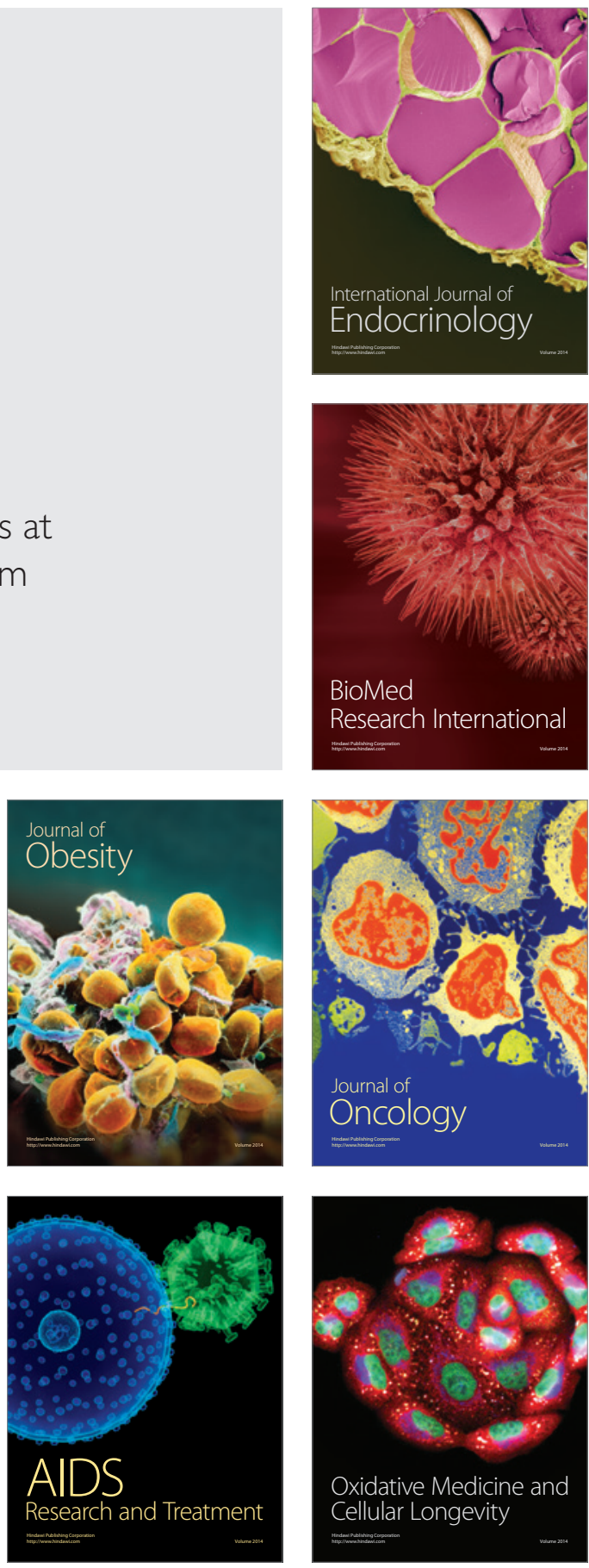